Motrivivência Ano XXIV, No 39, P. 35-56 Dez./2012

http://dx.doi.org/10.5007/2175-8042.2012v24n39p35

\title{
DOS EQUIPAMENTOS DE ESPORTE E LAZER AO PROBLEMA DA ACESSIBILIDADE NA ORLA DE ATALAIA: uma questão de política pública!
}

\author{
Cristiono Mezzaroba ${ }^{2}$ \\ Diego de Souza Mendes ${ }^{3}$ \\ Fábio Zobolit \\ Sérgio Dorenski ${ }^{5}$
}

\section{RESUMO}

Este estudo traz para o debate público a questão dos espaços públicos nos centros urbanos. Analisa a Orla da praia de Atalaia/SE no tocante aos equipamentos de esporte e lazer, sua infraestrutura física e condições de acessibilidade. De enfoque qualitativo/ descritivo demonstrou que há escassez de políticas públicas voltadas à acessibilidade dos cidadãos, bem como, no campo educacional, não há uma interação entre a escola (pública) e os espaços da cidade o que poderia ser viabilizado com passeios pedagógicos na Orla e seus equipamentos de esporte e lazer, por exemplo.

Palavras-chave: Espaço público; Esporte e lazer; Acessibilidade.

1 Para este artigo compilamos dois textos, Os equipamentos de esporte e lazer da Orla de Atalaia, de Mendes ET al (2012), e Acessibilidade e possibilidades de lazer: a pessoa com deficiência como foco de análise, de Almeida; Nunes e Zoboli (2012), ambos publicados no livro Projeto Orla: estrutura, equipamentos e usos da Orla na Praia de Atalaia em Aracaju/SE (MENDES; DORENSKI; MEZZAROBA, 2012).

2 Licenciado em Educação Física (UFSC) e Ciências Sociais (UFSC). Mestre em Educação Física (UFSC). Professor da Universidade Federal de Sergipe (DEF/CCBS/UFS) e pesquisador do LaboMídia (UFS/UFSC). Contato: cristiano_mezzaroba@yahoo.com.br.

3 Mestre em Educação Física (UFSC). Professor do Departamento de Ciências da Educação Física e da Saúde (UFS). Contato: diegomendes20@hotmail.com.br.

4 Doutor em Educação (UFBA). Professor do Departamento de Educação Física (UFS) e pesquisador do LaboMídia (UFS). Contato: zobolito@gmail.com.

5 Mestre em Educação Física (UFSC). Professor do Departamento de Educação Física (UFS), pesquisador e coordenador do LaboMídia (UFS). Doutorando da UFBA. Contato: dorenski@gmail.com. 


\section{INTRODUÇÃO}

Este ensaio é resultado das primeiras análises acerca dos equipamentos públicos de lazer, especificamente, na orla da praia de Atalaia em Aracaju/SE . Trata-se de expor, apontar possibilidades e perspectivas a partir da crítica da questão urbana no tocante aos espaços públicos de lazer. Entendemos que estudos dessa natureza são de vital importância para que se pense de modo democrático e participativo a cidade e suas particularidades, uma vez que o espaço público tem um caráter livre, além de proporcionar lazer garante a inclusão dos usuários com diferentes possibilidades econômicas, motoras, de sociabilidades etc. Não é estranho, principalmente em período de sufrágio universal, ouvir os diversos discursos de ampliação e melhorias dos espaços urbanos e isto tem sido um dos principais vetores das plataformas políticas para indicação do desenvolvimento dos estados ou do país, no entanto, não temos notado uma preocupação das condições de vida dos cidadãos e ainda, que o processo de escolarização esteja imbricado nessas melhorias.

Por isso, vemos a importância deste estudo, pois, tematiza, criticamente, os espaços e equipamentos públicos de esporte e lazer. Observa-se que a nova Orla da Praia de Atalaia se constitui em um cartão postal da capital sergipana. Reformulada com diversos equipamentos para as práticas esportivas e de lazer, configura-se como um local "ideal" no tocante às opções de lazer para os aracajuanos e sergipanos, bem como para os turistas que visitam a cidade. Esta particularidade é condição essencial para que todos (instância pública, sociedade, meio acadêmico, políticos, entre tantos) possam pensar e projetar ações que viabilizem a condição de cidadania que uma sociedade requer.

Foi transitando por este espaço que percebemos que ele se configura como uma das mais belas e equipadas orlas do país, sendo totalmente preparado para o turismo, o lazer e o entretenimento. Com $6 \mathrm{~km}$ de extensão, tem iluminação para uso noturno, espaços culturais e um complexo de bares e restaurantes. Possui equipamentos de ginástica, banheiros, ciclovia com mais de 5 mil metros de extensão, parques infantis, passarelas de acesso ao mar, espaço tenístico com 12 quadras, espaço de vôlei de praia, campo de futebol de areia e futebol society, parede de escaladas, complexo de esportes radicais com rampas de skate, estacionamentos com capacidade para 1.359 automóveis, além de um Centro de Arte e Cultura de Sergipe com $1.610 \mathrm{~m}^{2}$, que abriga 48 boxes. O espaço dispõe ainda de bancas de revistas, refletores de luz, telefones públicos, placas de informações, fontes luminosas, delegacia para turista, lagos, rede hoteleira, monumentos históricos, pista de Motocross e Kartódromo, entre outras.

Entretanto, foi também imerso neste ambiente que percebemos as contradições, muitas vezes ocultadas, que pairam sobre um espaço público como este. Assim, observamos que em alguns espaços e também

6 Referimo-nos ao "PROJETO ORLA: análise dos espaços e equipamentos de esporte e lazer da praia de Atalaia em Aracaju/SE e de suas formas de uso/ocupação", desenvolvida entre 2010 e 2011 por pesquisadores da Universidade Federal de Sergipe ligados ao "LaboMídia - Laboratório e Observatório da Mídia Esportiva" (Núcleo UFS) e demais colaboradores, aos quais agradecemos. 
em diferentes equipamentos de esporte e lazer são marcados pela lógica da privatização, a exemplo das quadras de tênis, do Kartódromo, o Oceanário (mantido pelo Projeto Tamar), a pista de Motocross, Praça de Eventos (que costuma abrigar quase que semanalmente eventos musicais pagos) e outros, que são administrados por entidades privadas. Com esta prerrogativa, parte da população local encontra dificuldade de acesso a bens e práticas situadas na Orla, fato este reforçado pela má distribuição de renda em nosso país que implica em diferentes níveis econômicos, bem como, pela ausência de políticas públicas atentas às necessidades sociais de transporte, segurança pública, manutenção dos equipamentos etc.

O objetivo deste ensaio é analisar pontos importantes que possam reacender as discussões no tocante à política pública nos centros urbanos a partir do "Projeto Orla" (que se configurou em uma pesquisa exploratória e materializou-se em um livro, sobre a infraestrutura, ocupação e acessibilidade dos equipamentos de esporte e lazer da Orla de Atalaia, em Aracaju, visando identificar pontos que possam sugerir melhoria da qualidade do serviço oferecido à sociedade, especialmente pelo setor público).

A relevância deste estudo é justamente publicizar as estratégias que identificaram e mapearam a infraestrutura dos equipamentos de esporte e lazer e os problemas da acessibilidade, bem como, o uso que as pessoas fazem dessa ocupação. Com isto, estamos colocando para a Administração Pública de forma (in)direta a necessidade de que se pensem, coletivamente, nos espaços urbanos, garantindo assim a cidadania plena.
Como explicam Mendes; Ribeiro; Mezzaroba (2012) este mapeamento e identificação, bem como de seus usos, pode tornar-se, para o administrador público, um importante instrumento de análise para pensar sobre os espaços públicos nas cidades, especialmente quando estamos nos referindo à Região Nordeste do país, em que há carência de efetivas ações no âmbito das políticas de lazer, seja pelas condições políticas historicamente consolidadas, ou, no caso do litoral, pelo fato dos espaços naturais representarem a garantia de oferta/ acesso ao lazer para população.

No que se refere aos procedimentos metodológicos, a pesquisa inicial - "Projeto Orla" - teve um enfoque descritivo com abordagem qualitativa (TRIVIÑOS, 1987; MINAYO, 2006). O projeto partiu para uma descrição interpretativa dos sujeitos e das situações envolvidas com o máximo de abrangência e detalhamento sobre os fatos e fenômenos investigados.

Foi com este intento que os pesquisadores fizeram a observação direta no espaço da Orla de Atalaia e seus equipamentos de esporte e lazer durante um período de seis meses, maio a outubro de 2010. Para uma apreensão mais fidedigna da realidade, o campo de pesquisa foi dividido em três setores (Norte/Central/Sul), com os pesquisadores organizados em pequenos grupos, com $2 \mathrm{~km}$ de extensão, aproximadamente, para cada subgrupo.

A captura dos dados foi realizada pelas observações (registradas em diário de campo, inclusive com registro de imagens com máquina fotográfica digital) e aplicação de questionários, com questões fechadas, a uma amostra constituída por 151 pessoas, realizada de maneira aleatória em toda extensão da Orla durante o período de um mês. 
Neste texto, partimos das análises a partir desses dados já coletados e publicados que consubstanciaram nossas inquietudes e reflexões acerca dos espaços públicos na Orla de Atalaia. Portanto, trouxemos dois aspectos que consideramos importantes para abertura do debate: primeiro, no que se refere à análise crítica da infraestrutura, dos equipamentos de esporte e lazer da Orla de Atalaia em Aracaju/SE, identificando as condições de manutenção, acesso e uso e outras relações com as políticas públicas; segundo, o debate posto estará na questão da acessibilidade, em que discutiremos os obstáculos encontrados em sua real aplicabilidade nos equipamentos da Orla.

\section{UM OLHAR SOBRE A ORLA DA PRAIA DE ATALAIA A PARTIR DA ESTRUTURA DOS EQUIPAMENTOS DE ESPORTE E LAZER}

Os dados aqui analisados foram obtidos junto a um público que tem idade entre 15 e 30 anos em sua maioria, embora tenhamos abordado desde crianças até idosos, sendo $64 \%$ do sexo masculino e $36 \%$ do sexo feminino. A maioria era moradores da cidade de Aracaju (92\%) e apenas $8 \%$ residiam em cidades próximas da capital sergipana. Com relação ao poder econômico do público da Orla, pudemos perceber que circulam naquele espaço pessoas de diferentes classes sociais. A maior parte pode ser considerada de classe média, com renda entre $R \$ 1.531,00$ e 5.100,00 reais ${ }^{7}$. Contudo, encontramos também pessoas com renda inferior ao salário mínimo e grupos que gozam de rendas consideradas altas para os padrões do país.

O público investigado tinha hábitos de frequência à Orla de Atalaia variados, o que equivalia entre uma e cinco vezes na semana. Enquanto uns disseram frequentar raramente, outros frequentavam diariamente. Isso faz com que a Orla esteja sempre ocupada por diferentes pessoas todos os dias.

No que se refere aos equipamentos de esporte e lazer, as observações de campo nos permitiram identificar um total de 52 equipamentos específicos de esporte e lazer e de 21 tipos diferentes, conforme Gráfico 1 abaixo:

Gráfico 1: Equipamentos de esporte e lazer da Orla de Atalaia

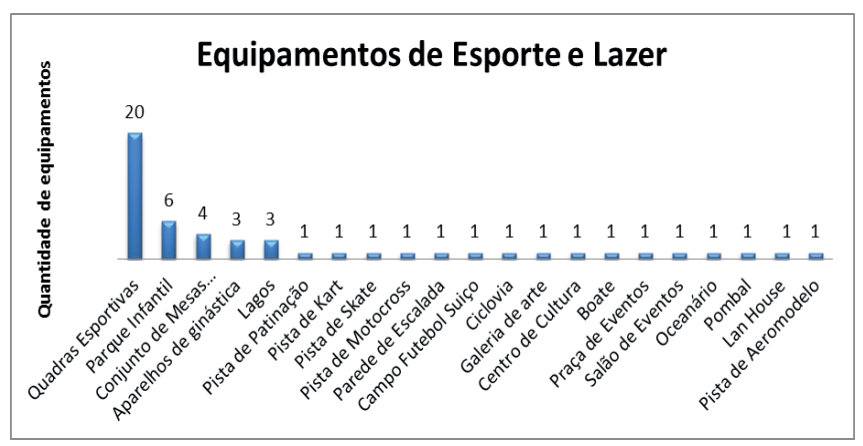

7 Valores baseados no salário mínimo de 2010, que equivalia a R \$ 510,00 reais (Medida Provisória n 474/2009). 
Todos estes equipamentos foram organizados/agrupados em seis categorias, conforme apresentaremos detalhadamente a seguir, que poderiam ser assim resumidas: Físico-Esportivo, Infantil, Jogos de Mesa, Culturais, Social e Outros.

\section{EQUIPAMENTOS FÍSICO-ESPORTIVOS}

A pesquisa revelou que a maior parte dos equipamentos da Orla de Atalaia destina-se às atividades físico-esportivas (cerca de 63,5\%). A ênfase nesses equipamentos pode advir de certa tradição consolidada no campo das Políticas Públicas de lazer focada em ações de construção de praças e/ou quadras esportivas (em muitos casos, uma única quadra "poliesportiva") como "tipos-ideais" de equipamentos para a cidade/população.

A prática esportiva como principal atividade de lazer é tradicionalmente aceita e tem raízes nas origens burguesas do esporte moderno. Conforme Proni (2002), o esporte era/é praticado em clubes fechados, é nessa leva que o modelo clubístico, popularizado entre a burguesia brasileira ao longo do século XX, apostou fortemente no esporte como "carro chefe" de suas ações. Os clubes continham suas quadras de tênis e piscinas, equipamentos típicos à prática de esportes da elite, com isso, os equipamentos de lazer esportivos passam a compor o imaginário social com relativa força no tocante a associação entre esporte e lazer.

De outro lado, se o esporte é associado ao lazer pela elite, o mesmo passa a ocorrer entre as classes populares. Historicamente as classes dominantes empreenderam esforços no sentido de reorientar as atividades populares, oferecendo a essas camadas populacionais atividades controladas, especialmente o esporte-espetáculo, restando a função de público aos menos favorecidos (MELO e JUNIOR, 2003). Evidentemente, as classes populares nunca se restringiram única e exclusivamente à condição de público, organizando-se para conquistar espaços para suas práticas. Aqui também que se encontram esforços nas construções de quadras em bairros distantes dos centros urbanos, o que reforça, neste caso, o entendimento de esporte como principal forma de lazer no tocante à lógica dos administradores públicos.

Embora a maior parte dos equipamentos de lazer da Orla de Atalaia seja de caráter físico-esportivo, eles contemplam ao menos três sub-tipos dessas práticas, conforme apresentamos abaixo:

a) Equipamentos de Esportes Tradicionais - A Orla de Atalaia contém 20 quadras esportivas dispostas por toda sua extensão. Na parte Norte da Orla fica o Centro Tenístico, composto por 12 quadras dessa modalidade, oportunamente na região em que se encontra a maior parte dos hotéis de luxo da Orla. Na Região Central da Orla temos uma quadra poliesportiva e um campo de futebol suíço, e na Região Sul, encontra-se a maioria das quadras esportivas e uma quadra poliesportiva.

As quadras de tênis, por serem administradas pela Federação Sergipana de Tênis, estão em melhores condições estruturais que as demais, considerando que esse órgão administrativo cobra uma taxa para 
o uso desses equipamentos. Dessa forma, embora as condições físicas das quadras estejam em bom estado de conservação, possuindo iluminação noturna, redes em bom estado etc., as condições de acesso do público encontram barreiras financeiras.

Além do complexo tenístico, pudemos constatar a existência de duas quadras poliesportivas, uma situada na Região Central e outra na Região Sul da Orla. A quadra situada na Região Central, apesar de bem conservada, permaneceu trancada durante quase todo o período de observação da pesquisa. Apenas em um fim de semana encontramos essa quadra aberta ao público. O mesmo se dá em relação ao campo de futebol suíço. Durante todo o período de observação não foi possível o registro desse campo aberto ao público, o que nos sugere que tais equipamentos estão sendo subutilizados, permanecendo mais como elementos da "paisagem" do que propriamente democratizado em relação a seu acesso e uso. Como a utilização do campo é limitada, a praia acaba sendo um refúgio para as inúmeras "peladas" e outras atividades futebolísticas.

Nas quadras da Região Sul há boas condições, apesar de alguns portões estarem quebrados, bem como as redes de proteção. É interessante destacar a utilização efetiva das quadras de vôlei, de handebol e futsal, inclusive no período da madrugada. A utilização dessas quadras pela comunidade em geral é bastante significativa, destacando a presença repetitiva dos mesmos grupos nesses equipamentos, especialmente os praticantes de futsal. Com menor frequência está o uso das quadras por grupos familiares (pais que levam seus filhos para aprender a andar de bicicleta ou até mesmo dar os primeiros passos nessas quadras), ou interessados em outras modalidades esportivas, como por exemplo, um grupo de jovens que se reuniam nessas quadras para praticar hóquei com patins. Um dos fatores que garante maior público nessa região (Sul) é sua proximidade com o principal terminal de ônibus da Orla, o que evidencia a íntima relação existente entre política de acesso e garantia de espaços de lazer.

b) Equipamentos de esportes diferenciados - Há equipamentos específicos para patinação, skate, corridas de kart e Motocross e parede de escalada. Esses equipamentos encontram-se distribuídos por toda extensão da Orla com maior concentração na Região Norte, onde estão as pistas de Motocross e skate, bem como a parede de escalada. A pista de patinação está presente na Região Sul e a pista de kart na Região Central.

Destacamos a pista de skate "Cara de Sapo", um dos maiores equipamentos esportivos do espaço da Orla e um dos únicos que é totalmente administrado e mantido pelo Estado. Porém é perceptível a diferença qualitativa na logística administrativa do equipamento - os refletores que iluminam a pista de skate são bem mais fracos do que, por exemplo, os que iluminam o complexo de tênis. Ao lado da pista fica a parede de escalada, praticamente inutilizada e com nítida falta de utensílios de segurança.

Outros equipamentos se encontram marcados pela lógica da privatização, sendo o acesso restrito ao pagamento de taxas, por vezes altas. É o caso das pistas de kart e de Motocross. Esses são equipamentos de grande porte, entre os maiores de toda Orla 
e contemplam boas condições físicas e de manutenção. Contudo, apenas tem acesso a esses bens o público pagante ou mesmo atletas das modalidades, filiados às associações e/ou federações, no caso, a Federação Sergipana de Motociclismo e a Associação Sergipana de Kart.

Essa "privatização" que está acontecendo na Orla de Atalaia se deve ao modelo de gerenciamento deste espaço público aracajuano/sergipano, que é realizado em parceria com entidades como associações e federações esportivas. Assim, tais entidades foram contempladas com locais específicos para suas modalidades esportivas e oferecem, em contrapartida, a responsabilidade de gerenciamento.

No caso do Kartódromo está previsto que o equipamento possa ser usado para treino dos membros da Associação Sergipana de Kart e eventos esportivos da mesma. Já nos horários em que essas atividades não ocorrem, a pista é dividida em duas partes para locação de corridas pelo público pagante. As tarifas para uso do Kartódromo durante o período de observação eram em média de $R \$ 25,00$ (vinte e cinco reais) por 15 minutos de corrida, sendo disponibilizados seis karts em cada pista. Outra possibilidade que resta ao público usuário da Orla é assistir as corridas de kart, visto que o equipamento conta com um espaço gratuito e que permanece aberto durante todo seu período de funcionamento. $\mathrm{O}$ uso da pista de Motocross é, ainda, mais restrito, sendo destinado apenas aos atletas da federação e a eventos esportivos.

A construção desses equipamentos de lazer se deu ao redor do que denominamos nesse trabalho de "região dos lagos", um espaço situado na parte central da Orla onde se encontram três lagos artificiais, com pistas para caminhada, corridas ou passeio de bicicletas, o Oceanário (Projeto TAMAR), entre outros. Este talvez seja o principal espaço contemplativo da Orla, visto que o cenário formado pela proximidade dos lagos com a praia oferece um visual edênico ao público. O contato, no entanto, desse espaço com o Kartódromo e a pista de Motocross produzem um dos maiores paradoxos arquitetônicos do local, pois a bela paisagem é invadida pela poluição sonora desses automotivos. Nesse sentido, podemos aferir que a interferência do processo de privatização da Orla influi não apenas em objeções econômicas ao acesso de determinados públicos ao lazer, como interfere também na estrutura ambiental do local.

c) Equipamentos para atividades físicas - Além dos equipamentos voltados ao esporte normativo, encontram-se na Orla equipamentos de lazer que estão associados às atividades físicas contemporâneas, práticas de movimentação corporal regradas pelos preceitos da vida ativa ou lazer ativo.

O estilo de vida ativo se oferece como uma forma de oposição aos males provenientes de uma vida sedentária. Nesse cenário, as atividades físicas aeróbicas como caminhar, correr, andar de bicicleta, nadar, dançar, praticar ginástica e musculação ganham destaque como possibilidades de prevenção das doenças cardiorrespiratórias e de aquisição de um bem-estar físico, mental e "social" (conforme sugere a OMS - Organização Mundial da Saúde).

Contudo, vale destacar que vários autores (FRAGA, 2006; SILVA, 2001; DEVIDE, 2002; FERREIRA, 1997; CARVALHO, 2009; 
entre outros) têm se questionado a respeito dos discursos que dão sustentabilidade aos preceitos da vida ativa, considerando que a saúde não está condicionada apenas à normatividade em relação à exercitação física e determinados comportamentos individuais (os já conhecidos e famosos discursos dos "estilos de vida", de caráter bastante comportamentalista), antes, consideram que a saúde está atrelada a questões políticas e sociais mais amplas, como o direito a moradia, saneamento básico, trabalho, renda, educação etc.

No quesito equipamentos de lazer voltados às atividades físicas, a Orla de Atalaia dispõe de três possibilidades:

1) A ciclovia pode ser considerada um equipamento de grande porte e seu principal problema é a falta de marcação adequada. Em determinadas partes se confunde com o espaço de trânsito das pessoas, colocando em questão a segurança dos transeuntes, sejam ciclistas ou não. Isso também ocasiona outro problema: em determinados pontos onde ela é atravessada por ruas ou acessos aos estacionamentos, sua continuidade se perde, não havendo em alguns casos uma visualização clara de qual seja o trajeto adequado para as bicicletas. Tal espaço é bastante utilizado, seja por pessoas andando de bicicletas, praticantes de caminhadas, corridas e mesmo por aqueles que apenas transitam pelo espaço.

2) Os equipamentos de ginástica se encontram na região Sul e na Região Central da Orla. Esses equipamentos não possuem qualquer tipo de orientação quanto ao uso, seja por meio de placas informativas sobre as formas de exercitação possíveis, ou mesmo pela presença de agentes/monitores especializados na prescrição, orientação e avaliação de atividades físicas. O público frequentador dos equipamentos ginásticos é constituído em sua maioria por jovens do sexo masculino e foi observado que esses aparelhos são subutilizados, talvez, no caso do período noturno, pela falta de policiamento e iluminação insuficiente, o que gera uma sensação de insegurança neste lugar. Não obstante, foram flagrantes as práticas de consumo de drogas licitas e ilícitas no local e proximidades.

3) Os lagos, que, além da função estética, são contornados por pistas para caminhadas/corridas/passeios de bicicletas, contam ainda com pedalinhos e caiaques para passeios e fonte com águas luminosas. São três lagos, mas somente dois deles são utilizados para as práticas de atividades físicas. O menor lago tem um caráter apenas de ornamentação. As condições estruturais de todos os lagos são boas, embora suas águas sejam impróprias para banhos. Há iluminação noturna adequada, cestos de lixo e bancos distribuídos ao redor de todo o trajeto de caminhada. Esses equipamentos são um dos mais frequentados da Orla, contém um público bastante amplo. Devido ao seu posicionamento próximo à rede hoteleira, observamos a presença de muitos turistas no local, 
especialmente em feriados e finais de semana, bem como uma ampla presença da população local, além de uma ampla área comercial que se estende ao seu redor.

\section{Equipamentos Infantis}

Verificamos a existência de seis parques, sendo cinco deles de pequeno porte e um de médio porte, denominado "Mundo Maravilhoso da Criança" (MMC). Com relação à localização, os equipamentos voltados às crianças estão distribuídos por toda extensão da Orla, três parques estão na Região Norte, dois ficam na Região Sul e o MMC na Região Central. Os parques pequenos possuem características em comum, possuindo brinquedos "clássicos" como escorregadores, gangorras, balanços e, alguns, caixas de areia. Esses parques são de acesso livre/gratuito e podem ser considerados em boas condições estruturais.

O MMC se constitui no principal equipamento da categoria infantil, não apenas por ser o maior parque da Orla, mas por ser uma espécie de "ilha", de reduto especialmente construído para o público infantil, com ampla infraestrutura. O MMC tem aos fundos o Kartódromo Emerson Fittipaldi, à sua direita uma delegacia de turismo (o que lhe confere, supostamente, maior segurança) e um salão de eventos. Já à esquerda há restaurantes, estacionamento e um setor com mesas de jogos.

Seu espaço é constituído por três mini-parques com gangorras, escorregadores, balanços etc., além de brinquedos geridos pela iniciativa privada como um carrossel, na parte central do parque, um mini-kart e dois espaços cercado para passeios em carrinhos eletrônicos. Nesse local encontram-se brinquedos itinerantes que também são ofertados pela iniciativa privada nos momentos de maior movimento, tais como pula-pula e até mesmo um trenzinho que circula pela Orla.

O público do parque é constituído basicamente por crianças acompanhadas de familiares e/ou responsáveis. Os brinquedos mais procurados são os carrinhos eletrônicos e o mini-kart. Algumas crianças ocupam os espaços públicos enquanto esperam a vaga nos brinquedos pagos. A intensa atividade comercial nesse espaço revela a inter-relação entre consumo e infância que perpassa o local. O MMC é um dos principais pontos de oferta de bens e serviços à população infantil.

Embora toda extensão da Orla tenha parques, outros espaços são apropriados pelas crianças para suas brincadeiras, como as quadras esportivas e os equipamentos ginásticos, o que nos permite considerar que os espaços infantis e o direito ao lazer para as crianças estão assegurados pelo poder público. Entretanto, constatamos que a existência de equipamentos de lazer voltados ao público infantil não bastam, sob a perspectiva das Políticas Públicas, para assegurar plenamente o direito ao lazer infantil. Conforme alerta Marcellino (2008), é preciso ser assegurado também políticas que incentivem a produção cultural "das" crianças, e não apenas a oferta de produção cultural "para" as crianças.

O MMC oferta ao público infantil produtos culturais projetados "para" as crianças enquanto mercadorias a serem consumidas. Este fato faz com que determinadas crianças tenham acesso a esses bens, enquanto outras são excluídas por questões econômicas. Os produtos destinados às 
crianças também não propiciam a interação, o convívio social, nem tampouco estimulam a criatividade e a produção cultural, uma vez que são brinquedos para práticas individuais.

Chamou-nos a atenção a pouca oferta de atividades culturais mais autênticas e com potencial artístico às crianças. Constatamos que são raras as atividades de teatro infantil, não há a presença de animadores socioculturais fomentando atividades lúdicas e culturais que permitam a integração das crianças, bem como a produção cultural por parte delas, como não há projetos de escolas visitando a Orla em atividades educacionais organizadas.

\section{Equipamentos para jogos de mesa}

Os equipamentos destinados aos Jogos de Mesa (dama e xadrez, jogos de cartas, dominó etc.), estão em toda extensão da Orla. Embora sejam equipamentos de médio porte, consideramos que a quantidade desses é pequena se comparada à categoria físico-esportivo. De modo geral, são pouco utilizados, especialmente para as funções as quais foram designadas, sendo comum o uso dessas mesas como espaço para alimentação, para bate-papo entre as pessoas, para consumo de bebidas alcoólicas, entre outros.

Consideramos que o uso dessas mesas para os jogos é escasso devido às condições precárias em que se encontram. As pinturas se encontram mal conservadas e a iluminação para utilização noturna estava em grande parte deteriorada e sem manutenção adequada. Em função da pouca luminosidade noturna, esses locais também são os mais isolados durante a noite, causando uma sensação de insegurança. $\mathrm{O}$ uso das mesas de jogos para outras finalidades atribui a esses equipamentos um caráter de multifuncionalidade, o que é, por nós, considerado positivo, visto que isto permite seu uso por grupos diferenciados e com intuitos distintos. No entanto, a omissão em relação a sua manutenção, para permitir seu pleno funcionamento para os jogos de mesa, traz consigo uma fragilidade no que se refere à conservação dessas práticas.

Peixoto (1995) revela a importância dos espaços de jogos de mesa para os idosos e sua sociabilização a partir da dinâmica que se estabelece nesses locais, pois, para este público, o que está em jogo é "passar o tempo", com critérios particulares na escolha dos parceiros e dos adversários (como jogar bem, jogar alegremente, jogar honestamente etc.), em que o importante é distrair-se, divertir-se, respeitando as regras do jogo escolhido.

Percebemos que este local não tem atraído o público idoso, nem qualquer outro público interessando em jogos de mesa, dada as condições estruturais para essas práticas ou mesmo pela ausência de incentivo à preservação dessas atividades por meio de projetos específicos. Há um ganho na apropriação multifuncional atribuída a esses equipamentos, mas por outro lado há ausência das práticas para as quais esses equipamentos foram desenvolvidos, ocasionando uma diminuição da apropriação por grupos de maior idade.

\section{Equipamentos sociais, culturais e outros}

Os equipamentos voltados à sociabilidade (tais como espaço de show, boate 
e salão de eventos), além de serem numericamente inferiores, são, em sua maioria, marcados pela lógica do dinheiro e de acesso pago. Nessa categoria está uma casa noturna/boate localizada na Região Central da Orla de Atalaia (um empreendimento privado), uma ampla praça destinada à realização de shows e um pequeno salão de eventos. Esses três equipamentos se situam relativamente próximos um dos outros e próximos à região de maior número de hotéis, o que ligamos este fato, à indústria do turismo.

Existem os equipamentos culturais, como o Oceanário e dois centros de Arte e Artesanato, além dos demais equipamentos que não se enquadraram nas categorias anteriores: lan house, pombal e uma área para aeromodelismo.

O Oceanário compõe a sede física do Projeto Tamar (Projeto Tamar-ICMBIO - Programa Brasileiro de Conservação das Tartarugas Marinhas - Instituto Chico Mendes de Conservação da Biodiversidade) em Aracaju. É um espaço de divulgação da cultura preservacionista, de apresentação de informações sobre animais marinhos e que, portanto, contribui para o processo de enculturação humana. Trata-se, em última análise, de um equipamento de lazer voltado ao patrimônio natural do país e, portanto, um bem de divulgação ecológica. Seu acesso é pago e a verba é revertida para a manutenção do projeto.

O Centro de Arte e Cultura J. Inácio é um espaço de exposição e comércio do artesanato local, sendo um local destinado às cooperativas e artesãos sergipanos. É possível encontrar peças em renda, bordados, cerâmicas, esculturas em barro, madeira e palha, peças de tapeçaria, redes e objetos de decoração em geral. Aos finais de semana o Centro abriga o Projeto Manifestações Populares, que tem por objetivo ser palco para diversas manifestações culturais do Estado.

A Praça de Eventos de Atalaia é o principal palco de shows e eventos de grande porte da Orla, como o Arraiá do Povo (durante as comemorações de São João, em junho) e a Feira de Sergipe, destinada à divulgação e comercialização do artesanato (realizada no início do ano). Trata-se de um espaço público em que, normalmente, são realizadas parcerias com a iniciativa privada para a promoção de eventos no local (como shows de axé, pagode, forró), o que, inclusive, já gerou polêmica e atenção do Ministério Público Estadual (MPE), que, em 2009, promoveu uma audiência referente à utilização indevida deste local para shows particulares. Para o promotor de Justiça do Meio Ambiente e Urbanismo, Renê Erba:

A Praça de Eventos da Orla é um espa-
ço público, constituindo-se um bem de
uso comum do povo, e o MPE entende
que só pode ser permitida a realização
de eventos que sejam abertos ao públi-
co em geral, isto é, ainda que realizado
por particulares, não haja cobrança de
ingresso [...]. Além do que se refere à
utilização do espaço público para fes-
tas pagas, o promotor levantou também
o problema da poluição sonora e da
degradação ambiental. [...] 'Pode estar
havendo uma degradação ambiental
por conta do lixo produzido e dos ba-
nheiros químicos, por exemplo, e uma
emissão sonora que passa dos limites,
caracterizando o crime ambiental'.7

7 As informações sobre esse caso foram divulgadas em alguns veículos de imprensa de Aracaju. Veja mais em http://www.infonet.com.br/cidade/ler.asp? id = 91924\&titulo = cidade 
O acesso à cultura e às atividades de sociabilidade na Orla de Atalaia são garantidos ao público. Contudo, o acesso pago a shows e eventos têm sido uma das maiores barreiras ao lazer cultural, além da carência de transporte (ônibus ou similares) na região (Norte) em que esses eventos acontecem. Com isso, o acesso pago aos equipamentos de lazer cultural e/ou social com finalidades lucrativas não apenas restringe a população local de usufruir desses bens, como exemplifica bem o caráter mercantil que o lazer assume frente à indústria do turismo no Estado. Não obstante, a resposta do Secretário de Estado da Infraestrutura de Sergipe (SEINFRA) à audiência citada anteriormente é contundente: "não podemos tomar uma medida que prejudique o turismo e o desenvolvimento da cidade" (Valmor Barbosa Bezerra) ${ }^{8}$.

\section{DEMAIS INFRAESTRUTURA}

Além dos equipamentos de esporte e lazer, a Orla de Atalaia possui uma infraestrutura que lhe dá suporte, tais como lixeiras, placas de sinalização, banheiros públicos, adereços de ornamentação e embelezamento (fontes luminosas e monumentos históricos).

Essa estrutura recebe manutenção todas as manhãs, de segunda a sábado, no que se refere à limpeza e jardinagem, sendo tais serviços realizados por uma empresa terceirizada. Além dessas equipes de limpeza, quando a Praça de Eventos é utilizada para shows ou apresentações de grande porte, uma equipe maior de funcionários de limpeza é designada para essa região. Ao que tudo indica, além da concessão pública do espaço, é o dinheiro do Estado que paga a limpeza e a segurança externa dos eventos que ocorrem nesse local, mesmo nos eventos de caráter privado, o que evidencia um tipo de parceria público-privada díspar.

Os questionários nos mostraram que $50 \%$ dos entrevistados julgaram a limpeza da Orla na região em que mais frequentam como regular e $44 \%$ avaliaram como bom, indicando satisfação ou satisfação parcial com esse aspecto. Apenas $6 \%$ consideraram a limpeza ruim. Toda extensão da Orla é repleta lixeiras, porém, muitas estão em más condições ou destruídas, seja por atos de depredação, ou mesmo pelo desgaste natural ocasionado pelas condições climáticas. Além disso, há um número insuficiente de banheiros. Nos seis quilômetros de extensão da Orla existem apenas três banheiros públicos e dois desses banheiros não ficam abertos ao público em boa parte do dia, sendo mais frequente sua abertura aos fins de semanas e à noite, apenas um dos banheiros ficava aberto das 8:00 às 20:00 horas todos os dias.

A segurança na Orla de Atalaia é representada pela presença de uma Delegacia de Turismo, uma Companhia de Policiamento Turístico (CPtur), da Polícia Militar, e um posto policial (alguns policiais militares de bicicletas fazem rondas em períodos específicos), além da presença de um posto de bombeiros e da vigilância invisível com câmeras de vídeos.

Apesar desta "segurança", constatamos que uma das maiores queixas do público está justamente nesse quesito. Apenas 
$18 \%$ dos entrevistados consideraram o local seguro, $30 \%$ julgaram a segurança ruim e $52 \%$ consideraram esse serviço regular. Realmente alguns trechos da Orla se apresentam menos seguros. A ronda de carro, por exemplo, pouco ajuda na segurança aos fundos da Orla, na região próxima à praia, local que só pode ser patrulhado a pé ou de bicicleta. Durante a noite essas áreas mais afastadas e próximas da faixa de areia também parecem ser as menos patrulhadas e há menos iluminação. Além disto, as ruas que se seguem próximas e aos fundos da rede hoteleira da Orla são um dos principais pontos de prostituição da cidade, que juntamente com a indústria do turismo atraem uma parcela da marginalidade interessada em furtos.

Esta sensação de insegurança por parte dos usuários da Orla de Atalaia acaba por interferir no sucesso de outros serviços que são oferecidos ao público. A Orla possui uma zona de cobertura de internet sem fio gratuita. Esta pareceu uma das medidas mais interessantes da Orla, integrando uma Política Pública de acesso à informação e também de lazer. Contudo, por motivos ligados à segurança no local, não constatamos em nossas observações sequer uma pessoa fazendo uso de um computador portátil (laptop) na Orla.

O transporte público na ou para a Orla também pode ser considerado como um dos aspectos relevantes para as Políticas Públicas de esporte e lazer em Aracaju. Muitos entrevistados indicam utilizarem carro próprio como meio de transporte para a Orla e um número pequeno dos entrevistados utilizam o transporte público e estes, concentram-se majoritariamente na Região Sul, local onde situa-se um dos terminais de integração de ônibus.
Os entrevistados que utilizam o meio de transporte público para a Orla de Atalaia considerou esse serviço ruim $(50 \%)$ ou regular ( $46 \%$ ), evidenciando que esta é uma das questões centrais para as políticas de esporte e lazer no local, visto que a população se sente mal ou medianamente atendida quando necessita do transporte público para ter garantido seu direito ao esporte e lazer nessa região da cidade.

A Orla de Atalaia possui uma estrutura de ornamentação e de bens culturais, tais como esculturas, monumentos em homenagem a personalidades nacionais e estaduais, que não foram levantados no estudo, e que se destacam positivamente pelo grande número de visitantes que aproveitam o cenário para registrar fotografias e vídeos. Outro aspecto desconsiderado nesse estudo foi a rede cultural-gastronômica que se estende por toda Orla, o que caracteriza uma fonte de lazer para parte dos seus frequentadores, devido à quantidade de bares, lanchonetes, restaurantes, barraquinhas de alimentação (com itens da gastronomia regional) que se fazem presentes ao longo de todo esse espaço.

Destacamos que nossa intenção foi emergir os pontos de maior relevância ao poder público para a avaliação e busca por melhorias das Políticas Públicas de lazer da cidade, que garanta à população de Aracaju e seus visitantes o pleno usufruto do direito ao lazer e ao esporte na cidade.

\section{ESPAÇO PÚBLICO E ACESSIBILIDADE}

A Constituição Federal coloca o lazer no mesmo nível e patamar de importância que o da educação, saúde, trabalho, moradia e segurança e o assegura como um 
direito social para o completo exercício da cidadania. Apesar de existirem leis específicas que garantem o acesso das pessoas com deficiência a espaços e equipamentos públicos de lazer, o descumprimento destas leis ainda é um grande empecilho que dificulta o deficiente desfrutá-los.

Os espaços na cidade sejam eles públicos ou privados, como parques, shoppings, teatros, cinemas, praças, quadras desportivas entre outros, de forma recorrente não apresentam as devidas medidas e não seguem as normas legais. Muitas vezes existe a rampa, mas sua angulação e declive impedem a autonomia do deficiente para acessá-la. Nas praças públicas constroem-se quadras, no entanto, com portas de entrada estreitas e batentes. Muitos brinquedos instalados em parques na sua constituição não oportunizam o acesso, por exemplo, as crianças com paralisia cerebral e outras deficiências motoras que necessitam de maior segurança para brincar.

Percebemos, e a pesquisa foi crucial para observarmos mais de perto, que muitas vezes as pessoas com deficiência acabam sendo privadas dos espaços simplesmente por questões de acessibilidade, com isso deixam de frequentar uma praça de lazer, praticar algum esporte, curtir um cinema no fim de semana, passear por um parque, frequentar restaurantes, visitar exposições de artes, ir a um estádio de futebol, assistir a uma peça de teatro ou a um concerto musical, entre outros no âmbito do lazer que oportunizam alegria e prazer a todos os sujeitos.

Outro aspecto, é que não é somente a acessibilidade um obstáculo a ser ultrapassado quando se fala em lazer para pessoa deficiente. O preconceito é muitas vezes uma barreira ainda maior. $\mathrm{O}$ preconceito que cerca esta temática faz com que essas pessoas se sintam incapazes e excluídas da sociedade que vivem. As pessoas com deficiência são vitimizadas por estigmas sociais por possuírem um corpo marginal - um corpo que fica à margem da normalidade. Nesse sentido, é importante que a diferença seja considerada e respeitada. Quando atribuímos valores às diferenças estamos estabelecendo relações de poder. A valoração cria hierarquizações simbólicas e nesse jogo tensivo a pessoa com deficiência carrega o peso social do estigma.

Nesta ótica é que devemos repensar o corpo como fator de (in)exclusão, na medida em que, antropológica e historicamente, ele sempre se constituiu enquanto um complexo de imagens - insígnias - que são utilizadas pelos mecanismos de poder e de ideologias sócio-culturais-econômicos, como um meio de se capturar o sujeito para aprisioná-lo e controlá-lo em alguma posição rígida e imutável, estabelecendo uma - suposta - essência em sua aparência material.

Com isto, queremos dizer que todas as pessoas têm direito à saúde, educação, esportes, cultura, turismo e lazer, sem discriminação de raça, cor ou de qualquer tipo de deficiência. Se um dos fundamentos da República Federativa do Brasil é o direito à cidadania, conforme disposto no art. $1^{\circ}$, II, da Constituição da República de 1988, não há como negar que a construção desta última perpassa, à luz do paradigma do Estado Democrático de Direito, pela implementação e efetivação de todos os direitos fundamentais nela descritos dentre eles o lazer.

Podemos destacar algumas leis mais específicas que orientam ações estruturais e atitudinais com relação à inclusão, a partir dos aspectos legais que norteiam a prática 
inclusiva, quando falamos de lazer, como a Lei 10.098 (lei de acessibilidade) ${ }^{9}$ que dispõe sobre diversos pontos fundamentais que norteiam as práticas inclusivas.

O Decreto 3.298/99 - regulamenta a lei $n^{\circ} 7.853$, de 24 de outubro de 1989, que dispõe sobre a Política Nacional para a Integração da Pessoa Portadora de Deficiência, consolida as normas de proteção e dá outras providências; citamos aqui o Art.46 - que versa sobre Cultura, Desporto e Lazer: "Assegura o oferecimento da prática de Educação Física nas instituições públicas e privadas. Acesso aos locais de prática desportivas e espaços públicos para o lazer".

A fim de que as pessoas com deficiência possam participar, em um mesmo nível com outros, em atividades recreativas, de lazer e esportivas, os Estados Membros adotarão as medidas apropriadas para:

(a) Incentivar e promover a participação, no maior alcance possível, de pessoas com deficiência em atividades esportivas gerais em todos os níveis;

(b) Assegurar que pessoas com deficiência tenham a oportunidade de organizar, desenvolver e participar em atividades esportivas e recreativas específicas para sua deficiência, e para esse fim, promover a provisão, em uma base igual com outros, de instrução apropriada, treinamento e recursos.

(c) Assegurar que pessoas com deficiência tenham acesso aos locais de esporte, recreação e turismo; (d) Assegurar que as crianças com deficiência tenham acesso igual na participação de brincadeiras, recreação, lazer e atividades esportivas, inclusive dentro do sistema educacional.

Percebemos que apesar desses direitos estarem explícitos na lei maior que é a Constituição, há necessidade da criação de outros Decretos-Leis para que seus direitos sejam contemplados. Neste sentido, ainda cabe mencionar o que temos de mais recente relacionado ao lazer, o Projeto de lei 575008 que regulamenta os playgrounds em área pública ou privativa de acordo com os seguintes artigos:

Art. $1^{\circ}$ Os "playgrounds" instalados em jardins, parques, áreas de lazer e áreas abertas ao público em geral, ainda que localizados em propriedade privada, conterão brinquedos adaptados para crianças portadoras de deficiência.

Art. $2^{\circ}$ As despesas decorrentes da aplicação desta lei correrão à conta de dotações consignadas no orçamento, suplementadas se necessário.

Os Direitos das pessoas com deficiência assinada pela Organização das Nações Unidas entre 192 países apresenta os principais direitos para quem tem necessidades especiais. Para as crianças, é assegurado o acesso à recreação e a áreas de esporte e lazer. Vejamos:

Seção V:

Da Cultura, do Desporto, do Turismo e do Lazer:

Art. 46. Os órgãos e as entidades da Administração Pública Federal direta e

9 Todas as leis citadas no texto que digam respeito à acessibilidade da pessoa com deficiência foram retiradas do site: http://www.dhnet.org.br/educar/dados/textos/rosario_espor.html (acessado no mês de dezembro de 2010) de autoria de Maria Do Rosário, intitulado O Esporte e o lazer à luz dos Direitos Humanos. 
indireta responsáveis pela cultura, pelo desporto, pelo turismo e pelo lazer dispensarão tratamento prioritário e adequado aos assuntos objeto deste Decreto, com vista a viabilizar, sem prejuízo de outras seguintes medidas.

I - promover o acesso da pessoa portadora de deficiência aos meios de comunicação social;

II - criar incentivos para o exercício de atividades criativas, mediante:

a) participação da pessoa portadora de deficiência em concursos de prêmios no campo das Artes e das letras.

b) exposições, publicações e representações artísticas de pessoa portadora de deficiência;

III - incentivar a prática desportiva formal e não formal como direito de cada um e o lazer como forma de promoção social;

Art. 48. Os órgãos e as entidades da Administração Pública Federal direta e indireta, promotores ou financiadores de atividades desportivas e de lazer, devem concorrer técnica e financeiramente para obtenção dos objetivos deste Decreto.

Parágrafo único: Será prioritariamente apoiada a manifestação desportiva de rendimento e a educacional, compreendendo as atividades de:

I - desenvolvimento de recursos humanos especializados;

II - promoção de competições desportivas internacionais, nacionais, estaduais e locais;

III - pesquisa científica, desenvolvimento tecnológico, documentação e informação;

IV - construção, ampliação, recuperação e adaptação de instalações desportivas e de lazer.
Todos os cidadãos têm direito ao lazer, a se divertir e a compartilhar momentos de vivência e emoções uns junto com os outros. Neste aspecto, percebemos que o espaço da Orla constitui-se numa área muito atrativa em termos de entretenimento para a população, sendo aí englobadas as pessoas com deficiência. No entanto, algumas dificuldades estruturais no referido espaço e seus equipamentos de lazer, já que na época em que foi construído ainda não havia algumas exigências legais para a acessibilidade da pessoa com deficiência, simbolizam o modelo de sociedade projetada para pessoas ditas "normais" e, apesar do surgimento e obrigatoriedade de sua implementação, nem tudo foi posto em prática. A perspectiva que se quer para acessibilidade passa pela:

Condição para a utilização com segurança e autonomia, total ou assistida, dos espaços, mobiliários e equipamentos urbanos, das edificações, dos serviços de transporte e dos dispositivos, sistemas ou meios de comunicação e informação por pessoa com deficiência ou com mobilidade reduzida (ALMEIDA, SOUZA NUNES, ZOBOLI, 2012, p. 88) ${ }^{10}$.

Com o intuito de analisar e avaliar as condições de acessibilidades arquitetônicas, comunicacionais e estruturais da segunda etapa da Orla de Atalaia, realizamos uma pesquisa a fim de elencar, esclarecer e citar as dificuldades encontradas no contexto da Orla de Atalaia quanto à acessibilidade e inclusão da pessoa com deficiência e a partir disso, propor considerações que possam viabilizar esses sujeitos a seu direito de acesso ao lazer. 
Foram escolhidos quatro equipamentos de lazer da Orla de Atalaia para serem analisados. Estabelecemos como critério de análise de acessibilidade a presença de rampas, piso tátil, sinalizações adequadas, adaptações estruturais, dentre outros elementos que asseguram o direito de ir e vir da pessoa com deficiência.

Na pesquisa inicial - Projeto Orla os pesquisadores coletaram os dados através de visitas às principais dependências da segunda etapa da Orla de Atalaia: Espaço Cultural, Praça de Eventos, Maravilhoso Mundo da Criança e quadras poliesportivas. Com sistematização semanal durante três meses - agosto, setembro e outubro - do ano de 2010, foram feitas observações, anotações de campo e também fotografias.

Sendo assim, passamos a apresentar no texto cada um dos espaços com a análise de seu respectivo equipamento de lazer no que tange a questões de acessibilidade:

No Centro de Arte e Cultura observamos, em relação às portas quanto à acessibilidade, que há um estreitamento já que segundo a ABNT (Associação Brasileira de Normas Técnicas), existe um parâmetro que na norma de 6.9.2.1, as portas, inclusive de elevadores, devem ter um vão livre mínimo de 0,80 m e altura mínima de 2,10 m. Em portas de duas ou mais folhas, pelo menos uma delas deve ter o vão livre de $0,80 \mathrm{~m}$. Sendo que estas portas estreitas dificultam a circulação do cadeirante neste ambiente.

A sinalização informativa nas portas em cada loja era inexistente, pois segundo ABNT, as portas devem ter informação visual (número da sala, função etc.) ocupando área entre 1,40 m e 1,60 m do piso, localizada no centro da porta ou na parede adjacente, ocupando área a uma distância do batente entre $15 \mathrm{~cm}$ e $45 \mathrm{~cm}$. A sinalização tátil (em Braille ou texto em relevo) deve ser instalada nos batentes ou vedo adjacente (parede, divisória ou painel), no lado onde estiver a maçaneta, a uma altura entre 0,90 m e 1,10 m. Esta sinalização daria a acessibilidade de comunicação aos deficientes visuais, pois o mesmo saberia os produtos comercializados nas lojas.

A pesquisa realizada detectou que em apenas um dos acessos ao centro cultural apresentava rampa, apesar de existirem três acessos. Ainda, este acesso é por trás do espaço cultural, onde o cadeirante teria que percorrer todo o centro, até chegar ao seu destino, dificultando assim o acesso ao local.

No que diz respeito às quadras esportivas o nível de sinalização tátil e visual que dá acesso às quadras inexiste, ou seja, não há placas informativas que estabeleçam uma comunicação para a acessibilidade e isto de certa forma, inviabiliza a existência das rampas (que já é um mérito) e um deficiente visual, por exemplo, sentirá dificuldade para saber que aquele ambiente é uma quadra esportiva.

Outro mérito foi a presença de piso tátil nas proximidades das quadras, mas, que paradoxalmente, segue uma reta e não dá acesso a estas quadras. Isto implica que, mesmo o deficiente visual querendo acessá-las irá passar ao lado das mesmas, uma vez que, o piso não vai até a entrada. Este é um fato a ser observado pela instância pública de forma imediata, pois há um aspecto bastante positivo em relação às quadras que é a presença de um ponto de ônibus bem à frente delas com rampas de acesso, o que facilita muito um cadeirante e outros mais que queiram vir até a Orla para praticar algum esporte. Os pontos de ônibus com rampas de acesso são uma constante em toda a Orla. 
Uma incoerência apontada pela pesquisa e percebida em todos os âmbitos e espaços sociais, que a nosso ver, é a materialização do desrespeito aos direitos das pessoas com deficiência, trata-se da presença de pessoas, com seus carros estacionados, nas vagas reservadas ao público deficiente. Isto era uma constante durante os três meses de observação permitindo assim, que estas pessoas gozem do uso de tais vagas sem a devida autorização.

Na Praça de Eventos é importante que se ressalte o que foi anunciado no início de nossa discussão, ou seja, não se justifica mais a falta de adaptações sob a alegação da lei, melhor/pior, que a lei não existia quando da reestruturação da Orla, esta talvez, seja a desculpa da incompetência administrativa, bem como, do desrespeito à cidadania. Hoje, é notório que os espaços públicos estão sendo mais frequentados pelas pessoas com deficiência, o que deveria ser uma preocupação maior em oferecer acesso a todos.

Os impedimentos à acessibilidade no espaço - Praça de Eventos - transitam do ponto de vista estrutural e aí, vai de um grande número de depressões no terreno, o que dificulta o cadeirante de transitar com maior segurança, até um número pequeno de rampas de acesso (somente duas) em volta desse espaço, limitando, assim, as pessoas com deficiência em chegar ao espaço de eventos. Além disso, não há pista tátil em todo o percurso da Praça de Eventos, chegando esta pista apenas até a entrada da mesma. Por não ter esse segmento táctil, a pessoa com deficiência visual que frequentar o local ficará sem ter noção de direção.

Por fim, verificamos que para passar da praça aos restaurantes e lanchonetes que ficam ao seu redor, inexiste o sinal sonoro que poderia oferecer segurança aos deficientes visuais para atravessar um trecho pequeno, mas "perigoso" quando não sinalizado.

O Mundo Maravilhoso da Criança deveria, na sua placa, ser acrescido: menos àquelas com necessidades especiais. Pois, principalmente no tocante à segurança delas, deixa a desejar. O espaço é recheado de vários brinquedos para o divertimento das crianças, mas, esses brinquedos para crianças ditas "normais" não apresentam dificuldades de segurança e manuseio ao brincar, no entanto, para as crianças que possuem algum tipo de deficiência, eles se tornam um tanto quanto impróprios, pois, as mesmas precisam de ajuda para ter acesso, o que não deveria acontecer num espaço destinado ao público infantil.

São barreiras e obstáculos desde o acesso aos brinquedos eletrônicos, até as dificuldades para subir escadas, além disso, os carrinhos são altos, o escorregador não é acessível. É verdade que para chegar aos balanços, gira-gira, gangorras, existe rampa de acesso, mas ao chegar aos brinquedos o chão é de pedra brita que dificulta a mobilidade. Acrescenta-se a isto, o fato do parque não possuir pista tátil, o que demonstra um descaso ao acesso do deficiente visual. Também ao redor do espaço existem poucas rampas de acesso e ausência de sinais sonoros.

Portanto, nosso entendimento, com base na lei 575008 referente aos playgrounds, mas, sobretudo, esclarecidos do dever do cidadão, vimos que tal documento não vigora ainda neste espaço (Orla), seja na esfera pública ou privada, o que implica na não efetivação do princípio de acessibilidade plena, limitando as possibilidades da criança com deficiência de usufruir de um 
dos direitos mais intrínsecos à condição da criança: o direito de brincar.

\section{CONSIDERAÇÕES FINAIS}

Esta pesquisa resultou em diversas publicações (Congressos, Semanas Científicas, Livro, capítulos de livro entre outros) e nos fez "mergulhar" na problemática do lazer e dos espaços públicos nas cidades e, em especial, Aracaju. Foi por este caminho que percebemos que a Orla da Praia de Atalaia constitui um importante lugar para o lazer dos aracajuanos, sergipanos e turistas em geral, no entanto, este espaço "público" já indica uma preocupação no tocante às condições estruturais (estado de conservação, acessibilidade, manutenção etc.) dos equipamentos de esporte e lazer, o que implica, no mínimo, numa ação mais incisiva do poder público para sua preservação.

Ouvindo os sujeitos, imersos no campo, fazendo levantamento de dados, percebemos que se torna crucial um trabaIho de preservação, manutenção e gestão da Orla e seus equipamentos, mesmo que uma parcela significativa - $46 \%$ dos entrevistados - tenha considerado as condições estruturais boas, ou seja, com isso queremos dizer que fica aqui um alerta para que se pense uma política constante voltada à sociedade nessa área.

Um aspecto importante observado pela pesquisa demonstra que a Orla é mais esvaziada durante os dias da semana e no período diurno. Esta peculiaridade poderia ser um ponto a ser observado no tocante às experiências com escolas e passeio ecológicos, de diversão, aprendizado, entre tantos que compõe o currículo oculto. Seria uma forma também de ocupar aqueles equipamentos - privados - que estão fechados (otimizando o uso em parceria com escolas e demais instituições educativas, ONG's por exemplo), principalmente no período vespertino, já que, conforme constatamos, no turno matutino, os espaços recebem limpeza e manutenção; e no período noturno, crianças e jovens utilizam as quadras jogando futsal, brincando nos parquinhos e pessoas fazem suas caminhadas, correm ou andam de bicicleta.

Este é um ponto importante (escolaorla), mas, percebemos, obviamente, que os frequentadores, são das mais variadas pessoas: de ambos os sexos; de todas as faixas etárias; com diferentes interesses nas suas práticas de lazer, entre outros. Sob esta ótica, acreditamos que projetos possam ser incrementados pensando nesta relação: (a) durante período de férias escolares poderia intensificar colônias de férias de caráter público, uma vez que, geralmente, essas colônias são pagas; (b) projetos que envolvam uma participação mais ativa de pessoas idosas; (c) projetos que viabilizem a prática inclusiva e a acessibilidade, dividindo tais iniciativas com a esfera privada, já que esta última acaba predominando e se beneficiando com tais ofertas, privatização que já é marcante na Orla, seja nos serviços, seja nos equipamentos, como a pista de Motocross, o Kartódromo e brinquedos, presente no Maravilhoso Mundo da Criança, entre outros que só reforça o processo de mercadorização do lazer num espaço eminentemente público da cidade.

Outro problema encontrado foi a falta de planejamento de transporte público adequado, ou melhor, de políticas de acesso da população. Apesar do sistema integrado de transportes em Aracaju, o custo é alto 
para as pessoas se deslocarem de seus bairros e acessarem os variados espaços que a Orla oferece. Parece-nos que ela fora pensada para a "Zona Sul" (em que pressupõe pessoas com maior poder aquisitivo) e para os turistas. Nessa mesma lógica pudemos perceber que as Políticas Públicas de lazer na Orla se resumem, apenas, à concessão do espaço (paradoxalmente, hoje sendo privatizado).

Essa perspectiva aqui apontada, que pressupõe a elaboração de projetos que atendam as necessidades da sociedade e que sejam de caráter público, não é só um anseio da pesquisa, mas, da sociedade de modo geral, pois, grande maioria dos entrevistados (94\%) são favoráveis à necessidade do poder público instituir programas, projetos ou outras ações que estimulem as práticas esportivas ou de lazer na Orla, o que seria expandido também com uma parceria entre Estado e universidades para o desenvolvimento de atividades de extensão à comunidade, especialmente no desenvolvimento do esporte comunitário, de práticas corporais e das práticas de lazer socializantes.

Percebemos o quanto o lazer é importante para sociedade, o que reforça a ideia de não sê-lo pormenorizado, pois, constitui-se numa rica ferramenta que tem a capacidade de incluir e democratizar o lúdico, humanizando o tempo, o espaço, as vivências, possibilita trocas objetivas e promove a inclusão. Neste sentido, colocamos aqui em xeque as políticas governamentais para assegurar o direito e acesso ao lazer que é garantido por lei, mas, que precisa ser a cada dia, referenciada. Isto implica numa posição política de todos nós diante da "coisa pública" e, sobretudo, numa postura que busque a inclusão de todos os seres humanos, independente de sua condição social, motora, econômica, ou seja, garantir um Estado democrático pleno.

Este alerta que explicitamos - antes de parecer um chavão e soar como apelativo "politiqueiro" - nasce com nossas observações no campo, onde presenciamos que diversos grupos sociais ainda têm sido impedidos de ter acesso a bens e serviços de cultura e entretenimento. Este dado vai para além do aspecto econômico das pessoas e sim, para o direito básico de ir e vir e de ter acesso ao lazer e à informação. Fato este que é mais perceptível quando observamos pessoas com deficiência, seja física, sensorial ou cognitiva, que têm esse direito constitucional violado em função dos espaços culturais de uso coletivo não estarem preparados para atendê-las.

Há de se esclarecer que a Orla de Atalaia contempla alguns avanços, principalmente, com relação à acessibilidade do portador de deficiência física/cadeirante. No entanto, ainda está distante de contemplar, com dignidade, pessoas com outros tipos de necessidades especiais. Isto se ratifica nos equipamentos que restringem o público e que visam atender um modelo de ser humano muito distante da diversidade humana. Assim, só ampliam e reforçam o processo de discriminação que existe desde épocas remotas de nossa história, mas, que hoje é inaceitável por tudo que foi conquistado pelo povo em busca de sua cidadania.

O caminho para essa tal cidadania plena é árduo, cheio de obstáculos e, obviamente, estamos a aprender como superar as dificuldades impostas que restringem as pessoas de modo geral e, as com deficiência, de modo específico, no que tange o acesso aos espaços de lazer. É preciso também verificar a existência de obstáculos que de 
certa forma, criam dificuldades para o uso dos espaços na Orla.

Concluindo, vimos que os dados indicam escassez de Políticas Públicas voltadas à acessibilidade dos cidadãos e, um dos objetivos desta pesquisa foi expor para sociedade e, em especial, para gestor público, a necessidade de estabelecer um compromisso político vislumbrando o lazer em conexão com as questões urbanas em geral, seja em relação ao transporte, à segurança, à educação, à cultura, à acessibilidade entre outras. O que implica, por parte da administração pública, incentivar e potencializar a apropriação desses bens da cultura pela população e esta, sentir-se incluída, sentir que seus direitos estão sendo respeitados. Mas, caso sejamos rotulados de sonhadores e que exigir isto seja uma Utopia, então, utópicos somos!

\section{REFERÊNCIAS}

ALMEIDA, R.K.C; SOUZA NUNES, P.M.; ZOBOLI, F. Acessibilidade e possibilidades de lazer: a pessoa com deficiência como foco de análise. In: MENDES, D. de S.; RIBEIRO, S.D.; MEZZAROBA, C. (org.) Projeto Orla: estrutura, equipamentos e usos da Orla na Praia de Atalaia em Aracaju/SE. São Cristóvão/SE: EDUFS, 2012, p.81-92.

CARVALHO, Y.M. de. $4^{\text {a }}$. Ed. O 'mito' da atividade física e saúde. São Paulo: Hucitec, 2009.

CONSTITUIÇÃO DA REPÚBLICA DO BRASIL, Distrito Federal, 1998.

DEVIDE, F.P. Educação Física, qualidade de vida e saúde: campos de intersecção e reflexões sobre a intervenção. Movimento, Porto Alegre, v.8, n. 2, maio/agosto 2002, p.77-84.
FERREIRA, M.G. Crítica a uma proposta de Educação Física direcionada à promoção da saúde a partir do referencial da sociologia do currículo e da pedagogia crítico-superadora. Movimento, ano IV, n. 7, 1997/2, p. 20-33.

FRAGA, A.B. Exercício da Informação: governo dos corpos no mercado da vida ativa. Campinas/SP: Autores Associados, 2006.

Legislação Federal Básica na Área da pessoa com Deficiência. Secretaria Especial dos Direitos Humanos/CORDE. Brasília - DF, 2007.

MARCELLINO, N.C. (Org). Políticas públicas de lazer. Campinas: Alínea, 2008.

MELO, V.A; JUNIOR, E.D.A. Introdução ao lazer. Rio de Janeiro: Manole, 2003. MENDES, D.S.; RIBEIRO, S.D.; MEZZAROBA, C. (org.) Projeto Orla: estrutura, equipamentos e usos da Orla na Praia de Atalaia em Aracaju/SE. São Cristóvão/SE: EDUFS, 2012.

MENDES, D.S. et al. Os equipamentos de esporte e lazer da orla de Atalaia. In: MENDES, D. de S.; RIBEIRO, S.D.; MEZZAROBA, C. (org.) Projeto Orla: estrutura, equipamentos e usos da Orla na Praia de Atalaia em Aracaju/SE. São Cristóvão/SE: EDUFS, 2012, p.13-50.

MINAYO, M.C.S. O desafio do conhecimento: pesquisa qualitativa em saúde. 9. ed. São Paulo: Hucitec, 2006. PEIXOTO, C.E. A sociabilidade dos idosos cariocas e parisienses. Revista Brasileira de Ciências Sociais. São Paulo, v 27, n.10, p.138-149, 1995. Disponível em: http://www.anpocs.org.br/portal/ publicacoes/rbcs_00_27/rbcs27_09. $\mathrm{htm}$. Acesso: out/2010.

PRONI, M.W. Brohm e a organização capitalista do esporte. In: PRONI, M.; 
LUCENA, R. (Org.). Esporte: história e sociedade. Campinas/SP: Autores Associados, 2002. (Coleção Educação Física e esportes).

ROSÁRIO, M. do. O Esporte e o lazer à luz dos direitos humanos. Disponível em: http://www.dhnet.org.br/educar/dados/ textos/rosario_espor.html. Acesso em: dez/2010.
SILVA, A.M. Corpo, ciência e mercado: reflexões acerca da gestação de um novo arquétipo da felicidade. Campinas: Autores Associados, 2001.

TRIVINÕS, A.N.S. Introdução à pesquisa em

Ciências Sociais: a pesquisa qualitativa em Educação. São Paulo: Atlas, 1987.

FROM SPORTS AND LEISURE EQUIPMENTS TO THE ACCESSIBILITY PROBLEM AT ORLA DE ATALAIA: a matter of public policy!

\section{ABSTRACT}

This study brings to public debate the issue of the public spaces in urban centers. It analyzes the Orla de Atalaia beach/SE regarding its sports and leisure equipments and its accessibility. With a qualitative/descriptive focus, this study has demonstrated that there is a shortage of public policies aimed at the citizens' accessibility, as well as in the educational field, where there is no interaction between the (public) school and the spaces around the city, which could be made viable by having pedagogical tours at Orla and by utilizing its sports and leisure equipments, for example.

Keywords: Public space; Sports and leisure; Accessibility. 